\title{
Beyond Indicators and Measures. Understanding the User's Reality Through a Qualitative Approach
}

\section{Aurora González-Teruel ${ }^{*}$}

\section{Introduction}

Nowadays in order to manage libraries it is no longer justifiable to think about the future based on what has been done in the past, or to act and make intuition-based decisions ${ }^{1}$. Now more than ever, it is necessary to make decisions based on empirical evidence obtained from knowledge about the internal and external settings of this library in order to adapt to them. Such a setting expects justifying the usefulness of investing the resources invested in this library, and in changing its direction towards users.

Yet these users have an ever-increasing offer of mechanisms to provide the information at their disposal. In this way, in recent years, the typical procedures of business organisation have been introduced in the management of information units, which generally correspond to the public sector. There is also a second matter: in professional discourse, the need to direct library management towards users is increasingly expected. As a result, similar discourse to the following can be frequently found in professional literature: «The objectives that libraries (and businesses) pursue when planning the use of social media are the same: earning more trust in the brand (reputation); satisfying users/customers (engagement); increasing sales (more library use and

* Historia de la Ciencia y Documentación, Universitat de València, Email address agonzal@uv.es. Web site last accessed: December 14, 2015.

1 Marie L. RAdFord, Foreword, in: Douglas Cook, Lesley Farmer (Eds.), Using Qualitative Methods in Action Research: How Librarians Can Get to the Why of Data, Chicago, Association of College and Research Libraries, 2011, p. XI-XII. 
user collaboration) and cutting costs» ${ }^{2}$. This argument is filled with terms like strategy, value, fidelity, segmentation, profitability, cost or benefit. These terms are typical of the management of organisations in a market setting, which other than focusing on users, centre on justifying the decisions made. Thus rather than users being the subject of action, they become its object. It is the library that acts because users will perceive a value, will feel satisfied or will use the services they have at their disposal more. Everything for users, but without users, who are a kind of management goal, a measure of success and justifying investment, rather than users being the main figure of action. In parallel to extending the use of the philosophy of library management, a new way of collaborating appears in the generation, use and exchange of information: web 2.0 and social media. This is a new setting where users play a more autonomous role. Consequently, libraries must consider the role they should play in an increasingly more information society.

In this context, the present work considers the necessity of changing the perspective from that which we professionals observe users and from where we make decisions, decisions in which users are absolutely involved. We can no longer think only about "adapting users' requirements" in terms of products and services, but must increasingly think about "blending into the user's reality". In other words, thinking about in what way it is possible to integrate the library into the user's reality. From the methodological viewpoint, this involves putting in second place measures of transactions between users and the library through library statistics, and focusing our interest in knowing users and their social setting. It is a matter of seeking in-depth knowledge about potential users rather than representative results. Not being limited to only evaluate the library with standard surveys about satisfaction, but finding out what is beyond the good or bad evaluations that users give, and acting accordingly.

So with such a change in perspective, reviewing what information behaviour research has contributed to users' knowledge of information, and also to library management with a user-centred approach, might prove useful. It is a research field whose theoretical and methodological debates about the study object and the most suitable methodology are similar, to a great extent, to those now considered in the library management and evaluation domain. Specifically, the present work puts forward the theoretical positions taken in IB research and their translation into a predominantly qualitative methodology. Finally, three methodological designs are provided that reflect the

2 Nieves González Fernández-Villavicencio - Alicia GonzÁlez-Martín, Demostrar el valor de la biblioteca en la web social: social media marketing. In: XII Jornadas Españolas de Documentación Científica. FESABID. 2013, 2013, p. 31. 
different perspectives taken when studying users of information systems. These three designs start from objectives and/or research questions that respond to different theoretical assumptions, which are also reflected not only in the analysis type undertaken, but also in the type of responses obtained.

\section{Theoretical and methodological debates in research into information behaviour}

\subsection{Theoretical foundations}

Information behaviour is defined as the study of any experience lived by an individual or group of individuals related with need, search, management, diffusion and use of information in various contexts ${ }^{3}$. As a specific research line within Library \& Information Science (LIS), its development starts precisely when the library no longer considers that it is a warehouse of books, but starts stressing its diffusing function. Yet despite former literature including such a background, it generally pinpoints the start of user studies in 1948, the year when the Royal Society Scientific Information Conference ${ }^{4}$ was held. In the first years of such studies, the user type that research centred on was experimental sciences and technology because of the way that the value that information had then was perceived in such contexts. Later other contexts were also considered target groups: social scientists, humanists and people in everyday settings. The methodologies of social sciences were also introduced when these new target groups were introduced.

While this research line was developing and progressing, the publication of a review chapter by Dervin and Nilan in 1986 in «Annual Review of Information Science and Technology» (ARIST ${ }^{5}$ ) about information requirements and uses became a major milestone. This chapter described a change in the user research paradigm; on the one hand, a traditional system-centered paradigm and, on the other, an emerging user-centred paradigm ${ }^{6}$. This duality between the system

3 Karen E. Fisher - Sanda Erdelez -Lynne McKechnie, Preface, in: Karen E. Fisher, Sanda Erdelez and Lynne McKechnie (Eds.), Theories of Information Behaviour, Medford, Information Today, 2005.

4 Rania Siatri, The Evolution of User Studies, «Libri», 49, 1999, 3, p. 132-141.

5 Brenda Dervin - Michael Nilan, Information Needs and Uses, «Annual Review of Information Science and Technology», 21, 1986, 1, p. 3-33.

6 Aurora González Teruel, La perspectiva del usuario y del sistema en la investigación sobre el comportamiento informacional, «Teoría de la Educación. Educación y Cultura en la Sociedad de la Información», 12, 2011, p. 9-27. 
perspective and the user perspective has since been a compulsory reference used to distinguish a more quantitative research type to address the user's observation of an information system, and another emerging one where the user is perceived in relation to information with a more qualitative approach. A consequence of this new paradigm was the start of a race, which resulted in an explosion of theoretical proposals for user studies, whose early beginnings came about in the 1970s and 1980s ${ }^{7}$. These theories intended to describe the information search process globally or holistically, and were interested in knowing certain aspects like the reason which leads people to seek information, irrespectively of the system they resort to, or the way they interact with a social, cultural or historic context. Since then, numerous theories have emerged, of which those by Pettigrew, Fidel and Bruce ${ }^{8}$ had a more far-reaching repercussion and were classified as cognitive approaches. They are based on the same grounds: cognitive aspects, or the model that each individual has of the world, condition the way that information is interpreted and employed. This approach centres on studying information behaviour from the perspective of an individual's cognitive and emotional motivations. Accordingly, two of the most cited theoretical models in recent years are included? The first is Ellis' model ${ }^{10}$, which centres on studying behavioural aspects of users when they interact with information retrieval systems. Its objective is to propose a series of individual patterns that users reproduce when seeking information and, from this, they determine specifications to design information retrieval systems. The second model is Kuhlthau's Information Search Process ${ }^{11}$. This model is based on a constructivist perspective of learning. It conceives information seeking as a building process in which users make progress by moving from uncertainty to knowledge. Uncertainty is considered a cognitive state that causes anxiety and lack of trust. In this way, different patterns are described to explain users' experience during the information search process. This process consists in a succession of these

7 David ElLIS, The Emergence of Conceptual Modelling in Information Behaviour Research, in: Amanda Spink, Jannica Heinström(Eds.), New Directions in Information Behaviour, Bingley, UK, Emerald Group Publishing, 2011, p. 17-35.

8 Karen E. Pettigrew - Raya Fidel - Harry Bruce, Conceptual Frameworks in Information Behaviour, "Annual Review of Information Science and Technology», 35, 2001, 1, p. 43-78.

9 A. González Teruel - Gregorio González Alcaide - Maite Barrios Cerrejón - María FRANCISCA ABAD GARCÍA, Mapping recent information behaviour research: an analysis of co-authorship and co-citation networks, «Scientometrics», 103, 2015, 2, p. 687-705.

10 DAvid ElLIS, A Behavioural Approach to Information Retrieval System Design, «Journal of Documentation», 45, 1989, 3, p. 171-212.

11 Carol C. Kuhlthau, Seeking Meaning. A Process Approach to Library and Information Services, Norwood, NJ, Ablex, 1993. 
stages or phases: starting, selecting, exploring, formulating, collection and presenting. Each one of the above stages is also seen from three points of view: affective (feelings), cognitive (reflections or thoughts) and physical (actions).

After consolidating information behaviour study, through the search of a theoretical foundation, critical positions have emerged in recent years that question the value of these theories, user centrality and the operationalisation of the context in which users seek information, among others. As to what these positions contribute to research in general terms, we can state that they are alternatives to not only individualism, but also to the lack of definition of what is social and its relation with seeking and using information since this context is not considered to go beyond the process and individuals' experience, but is implicit and constructed through these social processes.

From this perspective, the value of theoretical models is questioned. For instance, Olsson ${ }^{12}$ considers that the emergence of a new socio-technical phenomenon, like social networks or online communities, has evidenced shortcomings in predominant theoretical approaches. This is because they provide very few tools to study these aspects and state that studying the knowledge exchange that takes place in this medium, a practice as old as humanity, is once again being ignored, as has been traditionally the case. Likewise, McKenzie ${ }^{13}$ considers that recent theoretical models are restricted because they refer to limited aspects and represent successive searches to obtain information about a single problem, but do not include a wide variety of information practices, such as scanning surroundings, chance encounters and searches through intermediaries.

As regards the perspective taken, user centrality is also questioned. In line with this, Julien ${ }^{14}$ observed the poor interest shown in investigating the non-user of formal information systems, an aspect that can be considered system centrality as opposed to the user. Hence by analysing the relations between the user and the librarian according to Kuhlthau's Information Search Process, Tuominen ${ }^{15}$ sustains that user-centred discourse does not always address serving user requirements, but the system's requirements. Discourse does not necessarily

12 Michael R. Olsson, Ciphers to this Great Accompt. The Shakespearian Social Sense-Making of Theatre Professionals. In: Gunilla Widén, Kim Holmberg (Eds.), Social Information Research, Bingley, UK, Emerald Group Publishing, 2012, p. 17 - 42.

13 Pamela J. McKenzie, A Model of Information Practices in Accounts of Everydaylife Information Seeking, «Journal of Documentation», 59, 2003, 1, p. 19-40.

14 Heid Julien, Constructing "Users" in Library and Information Science, "Aslib Proceedings», 51, 1999, 6, p. 206-209.

15 Kimmo Tuominen, User-centered Discourse: an Analysis of the Subject Positions of the User and the Librarian, «The Library Quarterly», 67, 1997, 4, p. 350-371. 
free the user from the system's limitations, and so it does not easily allow the relations of unequal power between the expert librarian and an ignorant user to be left behind. As Talja ${ }^{16}$ states, the objective of providing help to people so they can move around in a modern knowledge setting and cope with it is inevitably based on a unilateral limited vision of knowledge, the system's vision. Hence McKenzie ${ }^{17}$ considers that many theoretical models, which describe the information search process, are based on the observation made by academic or professional users. So these models prove useful for describing the type of systematic search made in these settings, centre on analysing a current need, and consider a holistic approach, which intends to address any information behaviour. Nonetheless, these considerations are not always useful for knowing behaviour or information practices in an everyday life setting.

Talja ${ }^{18}$ considers that the cognitive point of view does not offer solutions to conceptualise the context in which users seek information, an aspect that has been extensively debated in the user-centered research of information. Olsson ${ }^{19}$ considered that, in their thirst for generalising information-seeking situations, existing models have become intercontextual models. In other words, as Courtright ${ }^{20}$ states, they omit the context or do not suitably represent the complexity, variability and mutual interactions of the contextual factors in the area of social networks, information technologies and organisational practices. Conversely when considering the context from a social perspective, this female researcher states that, from this perspective, both user and knowledge are considered actors and social facts, respectively. Accordingly, the actors in the information search process are social beings who construct information through interaction and language, and not only in their minds. Therefore, as actors' language reveals their social constructions of reality, the best way to understand the context for research is to analyse the discourse of these actors rather than merely observe their behaviours and record their points of

16 SANNA TALJA, Constituting Information and User as Research Objects: a Theory of Knowledge Formations as Alternative to the Information Man-theory, in: Pertti Vakkari, Reijo Savolainen, and Brenda Dervin (Eds.), Information Seeking in Context. Proceedings of an International Conference on Research in Information Needs, Seeking and Use in Different Contexts, London, Taylor Graham, 1997, p. 61-80.

17 P. J. McKenzie, A Model of Information Practices in Accounts of Everyday-life Information Seeking, p. 19-40.

18 S. TALJA, Constituting Information and User as Research Objects, p. 61-80.

19 Michael R. Olsson, Re-thinking our Concept of Users, «Australian Academic \& Research Libraries», 40, 2009, 1, p. 22-35.

20 Christina Courtright, Context in Information Behaviour Research, "Annual Review of Information Science and Technology», 41, 2008, 1, p. 273-306. 
view $^{21}$. A cognitive perspective of studying information behaviour takes the context as another variable, while this context from a social perspective constitutes the research object itself.

\subsection{Methodological foundations}

From the methodological viewpoint, investigating information behaviour does not go beyond the evolution of other social sciences in the $20^{\text {th }}$ century. After an initial phase, in which survey-based quantitative designs predominated, user research began to introduce qualitative designs. Wilson ${ }^{22}$ stated that the quantitative research methods being applied in the positivist tradition context were not adequate for studying human conduct. Likewise beyond the methodology guideline, the few techniques being employed were also criticised, as were the diversity and ambiguous nature of language when documenting the use of these techniques. Innovation was generally lacking and thorough experimental designs were inexistent ${ }^{23}$.

Extending the target groups in user studies, the emergence of the user-directed paradigm and, generally speaking, the shift towards social sciences in LIS ${ }^{24}$ all helped extend the qualitative methodology. In Tom Wilson's work On User Studies, a compulsory reference for information behaviour researchers, when describing one of its theoretical models that attempts to delimit the frontiers of user research, this author states that: «The vast majority of 'information needs' studies have been conducted under a relatively crude conception of the 'scientific method', using self-completed questionnaires as the main data-collection instrument. Social researchers of many kinds have become disenchanted with this model of research and are turning increasingly to a consideration of 'qualitative research' either as a complete alternative to quantitative research or, at least, as a preliminary» ${ }^{25}$. Otherwise, he defends a qualitative approach in user research as follows: "Qualitative research seems particularly appropriate to the study of the needs underlying information-seeking behaviour because: our concern is with uncovering the facts of the everyday life of the people being investigated; by uncovering those facts we aim to understand the needs that exist which press the individual towards

21 Ibidem.

22 Toм D. WiLson, Models in Information Behaviour Research, «Journal of Documentation", 55, 1999, 3, p. 249-270.

23 Herbert Menzel, Information Needs and Uses in Science and Technology, "Annual Review of Information Science and Technology», 1, 1966, p. 41-68.

24 D. Elus, The Emergence of Conceptual Modelling in Information Behaviour Research, p. 17-35.

25 Tom D. Wilson, On User Studies and Information Needs, «Journal of Documentation», 37, 1981, 1, p. 11. 
information-seeking behaviour; by better understanding those needs, we are able to better understand what meaning information has in the everyday life of people; and by all of the foregoing, we should have a better understanding of the user and be able to design more effective information systems ${ }^{26 "}$.

Nowadays, it can be stated that this research line has broadly assumed qualitative methodology assumptions, just as recent research works have demonstrated on an intellectual information behaviour research basis. One aspect that makes up this intellectual basis is precisely the qualitative methodology and, within it, other methodologies stand out, such as Grounded Theory ${ }^{27}$. Other methodologies include ethnography, case studies or phenomenology, to name just a few ${ }^{28}$. Apart from conventional questionnaires and interviews, whose hegemony is indisputable in this field ${ }^{29}$, other techniques are also employed, like observation, content analysis, focus groups, social network analyses or discourse analysis, among others ${ }^{30}$. The qualitative methodology has generally complemented and, to a great extent, favoured the theoretical developments achieved in recent years. As Gorman and colleagues ${ }^{31}$ stated, qualitative research is in tune with the increasing complexity of an information domain that requires flexibility and variability in data analysis. Generally speaking, the main contributions made by this approach boil down to four: a) assuming the conception of the user's reality as being subjective and multiple, rather than being determined by the reality of the information system; b) directing research to user observation where information problems emerge. So wherever the user is, he/she needs and uses information by introducing this user's context as an important research aspect; c) going deeply into various aspects of the information search process, and leaving or postponing the generalisation of results; d) developing inductive data analysis, in which concepts are

26 Ibidem.

27 A. González Teruel - María Francisca Abad García, Grounded Theory for Generating Theory in the Study of Information Behavior, «Library \& Information Science Research", 34, 2012, 1, p. 31-36.

28 Lynne E. F. McKechnie - Lynda BaKer - Martha Greenwood - Heidi Julien, Research Method Trends in Human Information Literature, «The New Review of Information Behaviour Research", 3, 2002, p. 113-125.

29 Heidi Julien - Jen Pecoskie - Kathleen Reed, Trends in Information Behavior Research, 1999-2008: a Content Analysis, «Library \& Information Science Research», 33, 2011, 1, p. 19-24.

30 L. E. F. McKechnie - L. BAKer - M. Greenwood - H. Julien, Research Method Trends in Human Information Literature, p. 113-125.

31 G. E. Gorman - Peter Clayton - Sydney J. Shep - Adela Clayton, Qualitative Research for the Information Professional: A Practical Handbook, London, Facet Publishing, 2005. 
organised and categories are built based on data, and not on former judgements, based generally on socio-demographic variables.

Nowadays however, confrontation between qualitative or quantitative research is not the main point of debate because their complementarity appears to have been demonstrated. The really interesting aspect is to look for the most suitable methodology in accordance with the research objective, regardless of its approach. So as previously described for theory, and from a methodological point of view in user research, some critical positions can be found with former research.

For instance, when analysing the methods adopted for user research in a users' everyday life context, Davenport ${ }^{32}$ considers that there has been very little reflexiveness on the researcher's position in the power networks that constitute academic work. Indeed when analysing the methods employed, these being the focus group, the critical incident technique ${ }^{33}$ and the time-line interview ${ }^{34}$, this female researcher classifies them as confessional methods since they are designed to help research to obtain truths or hidden meanings. The main point they have in common is that they intend to obtain information about activities and mental states that are not directly observable. Therefore as Olsson states ${ }^{35}$, results generate the representation of the social interaction between the researcher and the informant, but not of the user's cognitive structures. According to Davenport ${ }^{36}$, these methods also involve a researcher (a figure of authority or an expert) and one subject or more, so no interactions take place among peers; moreover, their objective is the intervention that improves a system, rather like providing some form of cure to the sick. So Olsson ${ }^{37}$ considers that the most outstanding information seeking models are those that result from their social-discourse context, and that they come over more as researchers' constructions than representations of the user's "reali-

32 Elisabeth Davenport, Confessional Methods and Everyday Life Information Seeking, "Annual Review of Information Science and Technology», 44, 2010, p. 533-562.

33 John Clemans Flanagan, The Critical Incident Technique, «Psychological Bulletin", 51, 1954, 4, p. 327-358.

34 Brenda Dervin, An Overview of Sense-Making Research: Concepts, Methods, and Results to Date, in: Annual Meeting of the International Communication Association, Dallas, TX. 1983, <http://communication.sbs.ohio-state.edu/sense-making/art/artdervin83.html>.

35 Michael R. Olson, Beyond "Needy" Individuals: Conceptualizing Information Behaviour, «Proceedings of the American Society for Information Science and Technology", 42, 2006, 1, p. 43-55.

36 E. Davenport, Confessional Methods and Everyday Life Information Seeking, p. 533-562.

37 M. R. Olsson, Re-thinking our Concept of Users, p. 22-35. 
ty". Along these lines, Carey, McKechnie and McKenzie ${ }^{38}$ observe that LIS researchers have begun to explore a discursive approach whose intention is to identify the means by which knowledge is generated and shared in a social context. This approach also expects critical thinking about the relationship between the observer and what is observed, and about the ways in which researchers jointly construct this relationship. So any change made in the perspective offered by the discursive viewpoint is a chance for these researchers to reflect on the research process itself, and also on what this process attempts to discover about people and their involvement in the world that surrounds them.

Basically, when examining the theoretical and methodological foundations of current IB research, at least two perspectives emerge, which have been described, among others, by Talja, Tuominen and Savolainen, ${ }^{39}$ or more recently by Tabak ${ }^{40}$. The first is the research that stems from the premise that users' cognitive aspects condition the way in which information is interpreted and used. From this perspective, this user context is considered another variable in the research process, a variable formed by social, cultural or historic aspects, among others. Thus the researcher role focuses on unveiling the content of cognitive maps or users' knowledge structures to understand how users interact with information. Apart from this cognitive perspective, there is another more social one that does not contemplate the user context as merely another variable, but as the research object itself. Users are considered actors and knowledge is a social fact, which implies that actors in the information search process are social beings who construct information through interaction and language, and not just in their minds. So as actors' language reveals their social constructions of reality, the best way to understand the research context is to analyse actors' discourse instead of merely observing their behaviour.

Behind such positions lie several theoretical assumptions related with the conception of reality, the researcher's role in the research process or what the main research object is. These different conceptions can be revealed when examining the three user-centred designs to do this: content analysis, social network analysis and discourse

38 Robert F. Carey - Lynne E. F. McKechnie - Pamela J. McKenzie, Gaining Access to Everyday Life Information Seeking, «Library \& Information Science Research», 23, 2002, 4, p. 319-334

39 S. Talja - Kimmo Tuominen - Rejjo Savolainen, Isms in Information Science: Constructivism, Collectivism and Constructionism, «Journal of Documentation», 61, 2005, 1, p. 79-101.

40 Edin Tавак, Jumping Between Context and Users: A Difficulty in Tracing Information Practices, «Journal of the Association for Information Science and Technology", 65, 2014, 11, p. 2223-2232. 
analysis. The three designs share the same data collection method, this being a qualitative interview. Yet the research objective or matter they are based on, and the analysis type to which they submit the information they obtain, differ. The aim is to not only reveal the usefulness of a procedure, but to also show that beyond the method, the research design responds to the theoretical assumptions that define what the research object actually is.

\section{User research from a qualitative perspective: content analysis, social network analysis and discourse analysis}

\subsection{Content analysis}

Content analysis is a set of procedures that interpret messages, texts or discourses based on quantitative or qualitative measurement techniques, whose objective is to prepare and process relevant data on production conditions or for these messages, texts or discourses to be subsequently used ${ }^{41}$. The content analysis procedure of texts begins by obtaining and selecting research data. This can be done by interviews ${ }^{42}$, an observation method ${ }^{43}$ or with contents from a series of written documents, e.g., scientific texts ${ }^{44}$, websites ${ }^{45}$, among others. The next step in the content analysis is to determine the analysis units, which are the basic analysable elements (words, sentences, paragraphs, etc.). Finally, the analysis itself commences, and consists in coding and classifying the analysis units by following either an inductive procedure by means of an open coding process, or a deductive process using the former categories or classifications. Quantitative and qualitative contents are generally distinguished. From a procedural viewpoint, what distinguishes them is basically the procedure used to select the sample of texts (probabilistic or non-probabilistic),

41 José Luis Piñuel Raigada, Epistemología, metodología y técnicas del análisis de contenido, «Estudios De Sociolingüística», 30, 2002, 1, 1-42.

42 Annu Sairanen - Rejo Savolainen, Avoiding Health Information in the Context of Uncertainty Management, «Information Research», 15, 2010, 4, <http://www.informationr.net/ir/15-4/paper443.html>.

43 MARIE L. RADFORD, Approach or Avoidance? The Role of Nonverbal Communication in the Academic Library User's Decision to Initiate a Reference Encounter, «Library Trends», 46, 1998, 4, p. 699-717.

44 Rebecca Green, The Profession's Models of Information: a Cognitive Linguistic Analysis, «Journal of Documentation» 47, 1991, 2, p. 130-40.

45 Stephanie W. Haas - Erika S. Grams, Readers, Authors, and Page Structure: a Discussion of Four Questions Arising from a Content Analysis of Web Pages, «Journal of the American Society for Information Science», 51, 2000, 2, p. 181-192. 
and the analytical procedures (induction or deduction) ${ }^{46}$.

To describe the content analysis application to the user study domain, the work by Ho and Crowley (2003) ${ }^{47}$ is taken as a reference, whose objective was to investigate the perceptions of students (users of a university library) of the reliability and exactness of the services that this library offered. This objective arose after conducting a previous study, which evaluated these users' satisfaction. This was done by administering a survey about satisfaction that followed the ServQual Model. Its results revealed discrepancies among users' expectations and perceptions of quality service on one of the dimensions, reliability. Despite these authors detecting this discrepancy, the results provided no further information other than a simple piece of data. Therefore, they set up this study, which employed a qualitative approach in order to not merely obtain a user satisfaction description, but to also understand the nuances of this dimension.

These authors employed several focus groups as the data collection technique, and a group interview to obtain information about the participants and the interaction among them. What the informants said was recorded and later transcribed completely or partially in order to be subsequently analysed. The basic units of this analysis were themes on the reliability of the service that appeared in the transcriptions. Next an inductive open coding procedure was set up, which consisted in thoroughly reading the text to be analysed and dividing it into fragments. These fragments were compared with each other, grouped into categories on the same theme, and labelled with a code. This code was a term or sentence that expressed the meaning of the analysed fragment ${ }^{48}$. In the work of Ho and Crowley ${ }^{49}$, this process produced five analysis themes or categories, which were separated inductively, and they responded to the research question; that is, the causes behind the poor perception of the reliability of the services offered by the library under study.

46 A. González Teruel - Maite Barrios Cerrejón, Métodos y técnicas para la investigación del comportamiento informacional: fundamentos y nuevos desarrollos, Gijón, Ediciones Trea, 2012.

47 Jeannette Ho - Gwyneth H. Crowley, User Perceptions of the "Reliability" of Library Services at Texas A\&M University: a Focus Group Study, "The Journal of Academic Librarianship», 29, 2003, 2, p. 82-87.

48 Hennie B. BoeIJe, Analysis in Qualitative Research, Los Angeles, Sage Publications, 2010.

49 J. Ho - G. H. CROwley, User Perceptions of the "Reliability" of Library Services at Texas A\&M University: a Focus Group Study, p. 82-87 
Table 1. Results of the content analysis in the research work of Ho and Crowley $y^{50}$

\begin{tabular}{|l|c|}
\hline TRANSCRIPTIONS & ANALYTICAL CATEGORIES \\
\hline $\begin{array}{l}\text { "I [have come to] assume that [LibCat] has } \\
\text { a lot more books in it than we actually } \\
\text { have [in the stacks]. So when I do searches, }\end{array}$ & Finding Materials on Shelves \\
$\begin{array}{l}\text { I automatically account for that and I } \\
\text { look for extra books." }\end{array}$ & \\
\hline $\begin{array}{l}\text { "There are four main primate journals } \\
\text { and two of them [are at another campus } \\
\text { library] and because of that, I end up not } \\
\text { getting those two as much because I have } \\
\text { to go over there. That is an issue." }\end{array}$ & Arrangement of Materials \\
\hline $\begin{array}{l}\text { I ordered books by interlibrary loan, they } \\
\text { came in, and nobody told me. So I [went } \\
\text { by to ask, found them] and checked them } \\
\text { out. A couple of days later [I was notified } \\
\text { by e-mail to] pick them up. [I was only } \\
\text { able to have them for two weeks instead } \\
\text { of four because of that. }\end{array}$ & Interlibrary Loan/Circulation \\
\hline $\begin{array}{l}\text { "I want it to be easy and not time } \\
\text { consuming...my time is very limited } \\
\text { and I have to go up flights of stairs and } \\
\text { elevators just to figure out what floor a } \\
\text { book is on." }\end{array}$ & \\
\hline $\begin{array}{l}\text { "I did an author search on the person's last } \\
\text { name, and brought up several names, but } \\
\text { not him. Then I did a search under book } \\
\text { title and then it brought up his name." }\end{array}$ & Searching the Online Catalog \\
\hline
\end{tabular}

\subsection{Social network analysis}

A social network is a structure made up by a series of nodes, or actors, some of which are connected to one relation or link, or more ${ }^{51}$. Studying information behaviour with a social network analysis centres the research on information exchange from a formal information flows viewpoint, but above all, from an informal information flows viewpoint. This, therefore, is a methodological approach that guides research towards user study (the network node) according to a social group (the set of relations) rather than towards studying the individual influenced by social factors, among others. In the 1990s, and from a

\section{Ibidem.}

51 David Knoke - Yang Song, Social Network Analysis, $2^{\text {nd }}$ ed., Thousands Oaks, Sage Publications, 2008. 
methodological viewpoint, Haythornthwaite ${ }^{52}$ described the potential of this method to study information exchange. However, it is not a widely used method in LIS, except in the bibliometrics context, and it has been more recently used to study online social networks.

With a view to illustrating the social network analysis procedure from the information behaviour viewpoint, we took the work by González-Teruel and Andreu-Ramos ${ }^{53}$ as a reference. The objective here was to test this approach to study information behaviour from a social perspective, centered more on relationships between people in a group than on these people's characteristics. In this way the social networks of a group of retired widowed women were studied, which is an information behaviour aspect in an everyday life situation. This population group was also at high risk of information exclusion as it is not a population that widely uses the Internet. Although recent studies $^{54}$ have demonstrated that the senior citizens population frequently visited the public library to, for example, read the press on a daily basis, this was more a male practice than a female one. Hence this senior citizen population group could benefit from the services of this library.

For data collection purposes, two techniques were used: a semi-structured interview and a questionnaire. The interview was based on that employed by Elfreda Chatman, a pioneer in introducing the social research methodology into LIS, to study the group of retired women from the social network perspective ${ }^{55}$. Thanks to this procedure, a general picture of the study group's iinformation behaviour obtained. By the second technique, the questionnaire, which was designed by partly following that employed by Johnson to study the information behaviour of a Mongalian population group ${ }^{56}$, information was col-

52 Caroline Haythornthwaite, Social Network Analysis: an Approach and Technique for the Study of Information Exchange, «Library \& Information Science Research» 18, 1996, 4, p. 323-342.

53 A. GonzÁlez Teruel - Carolina Andreu Ramos, Investigación del comportamiento Informacional a través del análisis de redes sociales, «El Profesional de la Información", 22, 2013, 6, p. 522-528.

54 Hilario Hernández SÁnchez - Rafael Ruiz Pérez, Estudio sobre los hábitos de lectura en la ciudad de Córdoba, «Boletín de la asociación andaluza de bibliotecarios», 96, 2009, p. 67-83.

55 Elfreda A. Chatman, The Information World of Retired Women, New York, Greenwood Press, 1992. E. A. Chatman, Framing Social Life in Theory and Research, «The New Review of Information Behaviour Research", 1, 2000, p. 3-17.

56 Catherine A. Johnson, Choosing People: the Role of Social Capital in Information Seeking Behaviour. «Information Research", 10, 2004, 1, < http://www.informationr.net/ir/10-1/paper201.html>. C. A. JoHnson, Social Capital and the Search for Information: Examining the Role of Social Capital in Information Seeking Behaviour in Mongolia, "Journal of the American Society for Information Science and Technology», 58, 2007, 6, p. 883-894. 
lected on each informant's social network. The data collected from the interviews were submitted to a qualitative content analysis to produce descriptive categories, which allowed the interviewed women's social networks to be contextualised. The data obtained by the questionnaire were used to graphically represent the network and its size.

Regarding data collection, it is worth stressing that one of the questions from the questionnaire was a name generator, an instrument devised to provide a series of names of the people related through some link to the informant ${ }^{57}$. In the work of González-Teruel and Andreu$\operatorname{Ramos}^{58}$, the women were asked to provide the names of the people to whom they would turn to if they needed help in their everyday life. For all these people, the informant also provided socio-demographic information and the type of relation they had with them. Based on this information, a graph was created of the personal or egocentric social network; that is, that which surrounds a node, known as an ego, and the other actors (alter egos) who share a given relationship ${ }^{59}$. When applying the results, Haythornthwaite ${ }^{60}$ states that this perspective helps model the information search process to guide new users with similar information needs, to make changes in an information system that can adjust to their behaviour, or to diffuse services that they do not employ.

Apart from the position generator, other instruments are available to extract social network nodes. For example, Marouf ${ }^{61}$ presents a full list, or roster, of the actors who form part of the informant's network, which indicates those people who can share information in the organisation context. According to Nan $\mathrm{Lin}^{62}$, this can also be used in the social capital theory context. In this way, the names of the known people within a given social structure are obtained. This begins with the social capital concept being understood as those resources embedded (including information) in a pyramidal social structure, which are mobilised by the network actors to solve certain questions. The

57 Félix Requena Santos, Redes sociales y cuestionarios, Madrid, Centro de Investigaciones Sociológicas (CIS), 1996.

58 A. González Teruel - C. Andreu Ramos, Investigación del comportamiento informacional a través del análisis de redes sociales, p. 522-528.

59 Alexandra Marin - Barry Wellman, Social Network Analysis. An introduction, in: Peter Carrington and John Scott (Eds.), The SAGE Handbook of Social Network Analysis, Thousand Oaks, CA, USA, Sage Publications, 2011, p. 11-25.

60 C. Haythornthwaite, Social Network Analysis: an Approach and Technique for the Study of Information Exchange, p. 323-342.

61 Laila NaIF Marouf, Social Networks and Knowledge Sharing in Organizations: a Case Study, «Journal of Knowledge Management», 11, 2007, 6, p. 110-125.

62 Nan Lin, Social Capital: A Theory of Social Structure and Action, Cambridge, Cambridge University Press, 2001. 
social relations among the network actors and the positions to which they have access determine the availability of these resources; thus people with more social capital are more likely to achieve success than people with less social capital.

In general terms, measures related with studying structural properties, or the model of the relationships within a network, of the links among nodes, or the position that several actors occupy within this network, can be applied from the social network analysis perspective to study Information Behaviour.

The most basic measures of structural properties are network size and density. Size refers to the number of actors who form part of the informant's network. From the information exchange viewpoint, a large network is considered to favour access to not only more information sources, but also to more varied ones. In the reference work, the mean network size was 19 nodes, the network with the fewest actors had 13 nodes, and that with the most had $27^{63}$. In the research by Johnson, the mean network size was 14 people. However, it is necessary to compare this figure with the studies done in similar contexts and with similar information collection instruments to evaluate this figure. For density, it is a matter of the number of existing links compared to the number of possible ones. We take the idea that information flows more quickly through well interconnected networks. However, a very dense network with a few links to external networks means that flowing information is recurrent, and thwarts information searches or leads to failed searches.

As regards the characteristics of the links, it is interesting to stress those studies based on Granovetter's ${ }^{64}$ theory of the strength of weak ties, which states that an individual's social network can be formed by strong or weak ties. Nonetheless, only weak ties act as links or "bridges" to another social network, through which it is possible to access the information that does not circulate through the network's own strong ties. Hence weak ties are not a potential source of access to new ideas, while stronger ties hinder this. In order to study information behaviour, Pettigrew ${ }^{65}$, for instance, described the relevance of nursing staff as providers of health information in a senior citizens network that they attended to because they provided senior citizens with information that strong ties were unable to obtain; e.g., ties with family relations.

63 A. González Teruel - C. Andreu Ramos, Investigación del comportamiento informacional a través del análisis de redes sociales, p. 522-528.

64 Mark S. Granovetter, The Strength of Weak Ties, «American Journal of Sociology », 78, 1973, 6, p. 1360-1380.

65 Karen E. Pettigrew, Waiting for Chiropody: Contextual Results from an Ethnographic Study of the Information Behaviour among Attendees at Community Clinics, «Information Processing \& Management», 35, 1999, 6, p. 801-817. 
Finally, in order to study positions within a network, one of the measures taken was brokerage, understood as the extent to which an actor plays a role to connect different groups. This was a measure from which several roles were appointed within groups that worked collaboratively. There were also other measure types that related with the actors and could be accessed within a social structure following the social capital theory: diversity and reach. Diversity is the number of different positions within a social structure to which an individual has access to. From the information behaviour perspective, the higher the diversity, the more options of finding the information required to solve a given informative problem. Reach is based on the idea that the better reach is, the more likely it accesses information resources. For example, from the information behaviour point of view, the better reach is in this social pyramid or in different networks through links, the more likelihood of, e.g., accessing information about better potential uses; in other words, more and better information ${ }^{66}$.

\subsection{Discourse analysis}

Discourse analysis «involves the careful examination of talk and texts in order to trace the ways in which discourses bring into being the objects and subjects of which they speak» ${ }^{67}$, and «is based on the premise that the words we choose to speak about something, and the way in which they are spoken or written, shape the sense that can be made of the world and our experience of it ${ }^{68}$,. Variety in traditions has contributed to its development, and has made it difficult to obtain a common definition of all the methodologies that study the use of language in a social context, which stem from disciplines like sociology, philosophy, psychology or linguistics, among others. So, for instance according to Carla Willig ${ }^{69}$, critical discourse analysis centres on the ways in which institutional discourses maintain power relations in a society, the analysis of conversation in microprocesses associated with using discourse in everyday conversations or, finally, the discourse analysis of psychology, which stresses how talkers use discourse resources to build particular versions of their experiences. From this last perspective, Gill ${ }^{70}$ took discourse (any form that talk

66 C. A. Johnson, Social Capital and the Search for Information: Examining the Role of Social Capital in Information Seeking Behaviour in Mongolia, pp. 883-894.

67 Carla Willig, Discourses and Discourse Analysis, in: Uwe Flick (ed.), The SAGE Handbook of Qualitative Analysis, London, Sage Publications, 2014, p. 341.

68 Ibidem.

69 Ivi, p. 341-353.

70 Rosalind Gill, Discourse Analysis: Practical Implementation, in: John Richardson (Ed.), Handbook of Qualitative Research Methods for Psychology and the Social Sciences, Leicester, British Psychological Society, 1996, p. 141-156. 
and text come in) as the object to study discourse rather than considering it a means to know a reality that goes beyond discourse itself. Moreover, the conception of discourse as something contructive, prepared from pre-existing linguistic resources, is used which the talker combines depending on its direction. Discourse is also social practice and is related to the world through these constructions; that is, language is not a neutral means to access a reality, but different social constructions.

In the LIS context, «the discourse analysis approaches lend themselves to projects exploring how people make sense of their information practices, examining the socially constructed understandings of information, information organizations, and information technologies, and applying these insights to improving the design of information technologies, search interfaces, and information services» ${ }^{71}$. Despite it not being a widespread approach in our discipline, some examples can be found in the information behaviour study domain. One of them is the work by Tuominen ${ }^{72}$, which investigates the position of the user and the librarian in professional user-centred discourses by analysing Kuhlthau's Information Search Process model. Similarly, Talja ${ }^{73}$ conducted a discourse analysis by studying the interpretative repertoires of both professionals and users of music libraries.

The work taken as a reference to analyse the discourse analysis application to study information behaviour, according to his procedure, was Reijo Savolainen ${ }^{74}$. This work investigates the discourses employed when some individuals talk about the Internet in an everyday life context. The research question, from which this male researcher started, focused specifically on knowing the way in which the Internet was spoken about and what discourses could be identified in these narrations. For this purpose, a series of semi-structured interviews was used with a population formed by people interested in personal development, i.e., studies done in one's free time, and who used the Internet to search for information for self-development requirements. Eighteen people were interviewed.

71 Lisa M. Given - Deborah Hicks - Theresa J. Schindel - Rebekah Willson, The Informing Nature of Talk \& Text: Discourse Analysis as a Research Approach in Information Science, «Proceedings of the American Society for Information Science and Technology», 51, 2015, p.1-4.

72 Кімmo Tuominen, User-centered Discourse: an Analysis of the Subject Positions of the User and the Librarian, "Library Quarterly», 67, 1997, 4, p. 350-371.

73 S. TALja, Music, Culture, and the Library: An Analysis of Discourses, Lanham, Scarecrow Press, 2001.

74 Reijo Savolainen, Enthusiastic, Realistic and Critical: Discourses of Internet Use in the Context of Everyday Life Information Seeking, "Information Research», 10, 2004, 1, <http://www.informationr.net/ir/10-1/paper198.html>. 
As Talja states ${ }^{75}$, with the discourse analysis, the interview did not intend to know the informant's point of view, or which processes were going through his or her mind. Its objective was to know regularities in language use. From this viewpoint, an interview seeks to know these regularities, descriptions and accounts on a theme, the evaluations on this theme, the different versions that appear, and the effects they have. In line with this, during the interviews conducted by Savolainen, ${ }^{76}$ informants were asked to describe how they used the Internet in their everyday life, what sources they preferred to use to acquire information for self-development purposes, and to describe the process they employed to search for a specific theme. The collected information was analysed by a discourse analysis based on the identification of interpretative repertoires of discursive psychology.

Interpretative repertoires are «sets of systematically related terms, often used with stylistic and grammatical coherence, and frequently organised around one central metaphor or more. They developed historically and are a key part of the "common sense" of a culture, although some are specific for certain institutional domains» ${ }^{77}$. In short, they would be linguistic resources recurrently employed to talk about reality. Talja ${ }^{78}$ summarises this analysis procedure in three phases. Firstly, it is necessary to analyse internal inconsistencies and contradictions in a participant's responses. The second phase consists in identifying regular patterns of variability in narrations: the descriptions that constantly emerge, and explanations and arguments in the speech of various participants. Finally, the third phase consists in identifying the basic assumptions and starting points that are the basis of a particular way of talking about a phenomenon.

In the reference work, three repertoires were obtained, which refer to three different ways of describing the Internet as a source of information. As mentioned earlier, these three repertoires are not the interviewees' thoughts or perceptions, but descriptions of the Internet, different versions of a reality. Nor are they versions of one informant or another, but descriptions that the same informant offers when faced with a question or given context.

The three repertoires were enthusiastic, realistic and critical. The

75 S. TALJA, Analyzing Qualitative Interview Data: the Discourse Analytic Method, «Library \& Information Science Research», 21, 1999, 4, p. 459-477.

76 R. Savolainen, Enthusiastic, Realistic and Critical: Discourses of Internet Use in the Context of Everyday Life Information Seeking.

77 Jonathan PotTer, La representación de la realidad. Discurso, retórica y construcción social, Barcelona, Paidos, 1998, p. 131 (Representing Reality Discourse, Rhetoric and Social Construction, 1996).

78 S. TALJA, Analyzing Qualitative Interview Data: the Discourse Analytic Method, p. $459-477$. 
enthusiastic repertoire was characterised by the optimism with which interviewees talked about the Internet as a source of information, and included recurrent expressions like fast, easy, versatile and interactive when participants talked about this means. The realistic repertoire indicated a more reserved discourse when talking about the advantages offered by the Internet as a source of information. Finally as part of its Internet version, the critical repertoire outlined the poor quality of the key information available online and it being badly organised, which make accurate information searches difficult.

Generally speaking, discourse analysis aims to know the social constructions made through language while, according to Wildemuth and Perryman ${ }^{79}$, the analysed text in the content analysis is treated as the description of an external reality, and aims to describe this reality through a series of analysis categories. Indeed the origin of both these directions lies in the theoretical assumptions that underlie both approaches.

The research question in discourse analysis aims to know how people talk about the Internet. It therefore assumes that knowledge of the reality is a linguistic product generated socially through communication, and not individually in each person's mind. So it starts with the conception of language as the previous condition of thought or, at least, as inseparable aspects, with language as the basis of all psychological activity ${ }^{80}$. Thus it changes the research approach from one that entails understanding individual users' needs, situations and contexts to knowledge production in these users' discourses ${ }^{81}$.

Unlike these considerations, a study based on the content analysis of what people think about the Internet would be based on the idea that their language would be the user's window of reality, and that this reality would be conceived by this user with a series of cognitive processes. Talja, Tuominen and Savolainen ${ }^{82}$ believe that this cognitive perspective begins with the conception of the user who acts as an information processor, and also from the generation of knowledge in this user's mind because cognitive maps and knowledge structures form according to his/her experiences and observations. During this process, the social context can be influential as another variable, but not as the research object. The researcher could, therefore, evidence all this through interviews or other methods.

79 Barbara M. Wildemuth - Carol L. Perryman, Discourse Analysis, in : Barbara M. Wildemuth, (ed.), Applications of Social Research Methods to Questions in Information and Library Science, Westport, Libraries Unlimited, 2009, p. 320-328.

80 Vivien Burr, An Introduction to Social Constructionism, London, Routledge, 1995.

81 S. Talja, K. TuOminen - R. Savolainen, Isms in Information Science, p. 79-101.

82 Ibidem. 


\section{Conclusion}

The three designs have been presented, and they offer different results despite them being based on a similar information collection procedure. They are research works that have been designed according to different assumptions in which the research question intended to obtain an interpretation of a group of users' perceptions of a library, the way they exchange information in a social context, and how reality is built by means of language.

These are all different aspects of information behaviour but, above all, they reflect various conceptions of what user research must be. So user reality, his/her social world as a preferable information search setting or the reality built by a group of users is taken as the study object.

Despite not being a homogeneous set of procedures, qualitative research has enabled the user in this research to direct the focal point of interest on the same context in which information is sought, used or exchanged, perhaps by leaving the study of the transactions between the user and information systems to one side. It has also enabled the interpretations and conclusions made in the research to be based on that observed rather on judgements made a priori based on socio-demographic characteristics, whose influence on information behaviour is important, but not decisive. It has also helped research understand the reason why people search (or not) for and convert this information into requirements that a new information system must cover in order to suitably satisfy its users. All this can be assumed from the library management and evaluation viewpoint if it intends to "be integrated into the user's reality" rather than "be adapted to requirements", users do not often perceive the need for brokerage in information searches. In any case, complexity does not lie in the method, but in choosing the procedure according to the research objectives or question, and beyond all this, in choosing the best design to allow us to acquire information to improve the system. 